N. J. Wesensten - T. J. Balkin · H. Q. Davis

G. L. Belenky

\title{
Reversal of Triazolam- and Zolpidem-induced Memory Impairment by Flumazenil
}

Received: 16 January 1995 / Final version: 21 April 1995

\begin{abstract}
The effects of flumazenil, a benzodiazepine receptor antagonist, on triazolam- and zolpideminduced memory impairment were investigated. Sixty subjects received oral triazolam $0.5 \mathrm{mg}$, zolpidem $20.0 \mathrm{mg}$, or placebo at $10 \mathrm{a} . \mathrm{m}$. $(n=20$ per drug). Ninety minutes later, half of the subjects $(n=10)$ in each oral drug group were administered flumazenil $1.0 \mathrm{mg}$, while the remaining half received placebo (normal saline), through indwelling venous catheters. Learning/memory tests (including Simulated Escape, Restricted Reminding, Paired-Associates, and Repeated Acquisition) were administered at that time, and at 1.5-h intervals over the next $6 \mathrm{~h}$. Triazolam/placebo and zolpidem/placebo drug combinations impaired memory on all tests (all $P \mathrm{~s}<0.05$ ). However, the triazolam/flumazenil and zolpidem/flumazenil groups showed no evidence of impairment during any test session. These results demonstrate that flumazenil $1.0 \mathrm{mg}$ rapidly and lastingly reverses memory impairment caused by agonists of the benzodiazepine receptor. Furthermore, nonsignificant trends suggested that performance of the placebo/flumazenil group was consistently better than that of the placebo/placebo group, denoting a possible role of endogenous benzodiazepine agonists in natural sleep/wake processes.
\end{abstract}

Key words Flumazenil - Triazolam $\cdot$ Zolpidem · Memory $\cdot$ Benzodiazepine antagonist

\section{Introduction}

Benzodiazepine (BZ) receptor agonists induce their sedative, anxiolytic, and anticonvulsant effects by

N. J. Wesensten ( 0$) \cdot$ T. J. Balkin $\cdot$ H. Q. Davis

G. L. Belensky

Department of Behavioral Biology, Division of Neuropsychiatry, Walter Reed Army Institute of Research, Washington

DC 20307-5100, USA potentiating the actions of the inhibitory neurotransmitter gamma aminobutyric acid (Farb et al. 1984). Flumazenil (Romazicon) is a BZ antagonist which binds with roughly equal affinity to both of the central (neuronal) benzodiazepine receptor subtypes (BZ-1 and BZ-2 - Siegart and Schuster 1984), and is thought to have little intrinsic effect on GABA-ergic transmission (Polc et al. 1981). Although some studies with animals suggest mild agonist-like activity (File and Pellow 1986), flumazenil has few or no measurable effects in humans, even at 100 times the dose used therapeutically for reversal of BZ-induced sedation (Darragh et al. 1983).

The efficacy with which flumazenil reverses BZinduced sedation has been well documented (see Brogden and Goa 1991). However, the extent to which flumazenil reverses other BZ agonist-induced effects, particularly memory impairment, is less clear. In many of the relevant prior studies (reviewed by Ghoneim 1992) which suggest reversal of BZ-induced memory impairment by flumazenil, subjects were recruited from clinical populations (e.g., surgical patients) and memory testing was insensitive to all but the most obtrusive and conspicuous memory deficits, e.g., recall or recognition of a single picture item, or subjective ratings of memory and performance. On the other hand, in those prior studies in which BZ-induced memory impairment was not completely reversed by flumazenil, results were potentially attributable to methodologies in which flumazenil doses were titrated to minimum levels required for reawakening, rather than minimum levels needed for restoring full alertness. In addition, failure to include appropriate placebo control conditions in several studies dictates that these studies be interpreted cautiously (Ghoneim 1992).

In controlled studies using healthy volunteers, flumazenil has been shown to reverse amnesia induced by diazepam (Dunton et al. 1988), lormetazepam (Dorow et al. 1987), midazolam (Dunton et al. 1988; 
Short and Galletly 1988; McKay et al. 1990), lorazepam (Dunton et al. 1988; Preston et al. 1989), and flunitrazepam (Gentil et al. 1989). However, flumazenilmediated reversal of the amnestic effects of more commonly used hypnotics, and the time course of flumazenil's antagonistic effects, have received little attention. Triazolam (Halcion) and zolpidem [Stilnox (Europe), Ambien (U.S.)] are two short-acting hypnotics with similar pharmacokinetic profiles: mean time to peak plasma concentrations of 1.3 and $1.8 \mathrm{~h}$, and elimination half-lives of 2.6 and $2.4 \mathrm{~h}$, respectively (Friedman et al. 1986; Thenot et al. 1988). Both drugs are thought to exert their hypnotic effects via agonist action at the benzodiazepine receptor. Triazolam binds with approximately equal affinity to BZ-1 and BZ-2 receptor subtypes; zolpidem binds preferentially (with six times greater affinity) to the BZ-1 subtype (Langer et al. 1988). Despite differential receptor subtype affinity, both triazolam and zolpidem have been shown to produce potent memoryimpairing effects at time of estimated peak blood concentrations in normal, healthy adults (e.g. Balkin et al. 1992; Berlin et al. 1993; Roehrs et al. 1994). In addition, there is some evidence that triazolam's memory-impairing effects last up to $8 \mathrm{~h}$ post-administration (Penetar et al. 1989).

The usefulness of flumazenil for reversal of both zolpidem (Lhereux et al. 1990) and triazolam (Kelly et al. 1988; Burkhart and Kulig 1990) overdose has been documented. In those studies, administration of flumazenil caused rapid re-awakening, but its effects on drug-induced memory impairment were not evaluated. In a recent study by Patat et al. (1994) reversal of zolpidem-induced sedation and memory impairment by flumazenil was reported; however, (a) only minimal memory impairment was evident in the group of subjects receiving zolpidem alone (perhaps due to an insensitive test of memory and/or an insufficient dose of zolpidem), and (b) no statistical analyses were presented.

The present study was conducted to determine whether flumazenil would reverse memory impairment caused by both the BZ subtype-nonspecific agonist triazolam as well as the newer BZ-1-specific agonist zolpidem. The present investigation improves upon previous studies in that flumazenil was administered doubleblind in a fixed dosage rather than titrated for awakening. In addition, triazolam and zolpidem were administered in dosages known to cause memory impairment on tests used in the present study $(0.5$ and $20.0 \mathrm{mg}$, respectively - O'Donnell et al. 1988; Balkin et al. 1992). Flumazenil was administered (and memory was tested) at peak amnestic effects of triazolam and zolpidem. The dosage of flumazenil used in the present study ( $1 \mathrm{mg}$ intravenous) is the highest currently recommended dose (U.S.) for reversal of benzodiazepine-induced sedation during anaesthesia (Physician's Desk Reference 1994).

\section{Materials and methods}

Subjects

Subjects were 60 healthy non-smoking male volunteers (age range $18-39$ years, mean $=24.5$ ) who responded to advertisements posted at local universities. Informed consent was obtained, and included an explanation of all procedures as well as possible drug side effects. Subjects were screened for past and current physical/mental health problems, sleep problems, and drug use. They were instructed to abstain from alcohol and psychoactive drugs starting $48 \mathrm{~h}$ prior to the study. Compliance was determined with a urine drug screen on samples collected on the morning of the study. Payment was $\$ 125$ for completion of the study, with a possible $\$ 50$ performance bonus (described below).

\section{Memory testing}

Restricted Reminding Test (RRT)

A modified version (O'Donnell 1981) of the Buschke test (Buschke and Fuld 1974) was used, and is described in detail elsewhere (Balkin et al. 1992). Briefly, subjects attempted to recall 20 words from a single semantic category. On subsequent trials, subjects were read only those words not recalled during the preceding trial. Five forms of the test were administered in a counterbalanced order across sessions. A sixth form was used for practice on the evening prior to drug administration. Dependent measures included total misses (number of times a word was not remembered; 160 possible per session) and intrusions (number of unique, non-list items, i.e., errors of commission).

\section{Paired-Associates test $(P-A)$}

Forms $\mathbf{A}$ and $\mathbf{B}$ of the Weschler Memory scale Associative Learning sub-test were used, as described elsewhere (O’Donnell et al. 1988). Briefly, subjects attempted to recall the second word of a pair. Three trials of the same ten word pairs (one form) were presented for the immediate recall phase, and errors were corrected. The delayed recall phase consisted of one trial in which errors were not corrected. Order of forms A and B was counterbalanced among subjects. Each trial was scored for number of correctly recalled associates.

\section{Simulated escape test}

This task is described in detail elsewhere (Balkin et al. 1992). At $1.5 \mathrm{~h}$ post-oral drug, subjects were instructed to follow ten large blue directional arrows through laboratory corridors. At $6 \mathrm{~h}$ postoral drug, subjects attempted to retrace the escape route without arrows. Each attempt was scored for number of wrong turns.

\section{Computerized Performance Assessment Battery (PAB)}

Two tests from the Walter Reed Performance Assessment Battery (Thorne et al. 1985) were administered - the Repeated Acquisition test and a computerized version of the Stanford Sleepiness Scale.

\section{Repeated acquisition}

In this task, subjects attempted to learn a sequence of 12 keystrokes, using the "8", "6", " 2 ", and "4" keys (i.e., the "up", "right", "down", 
and "left" arrow keys, respectively) on a numeric keypad. On trial 1, subjects guessed at each keystroke until the correct one was chosen (causing a box to light up on the CRT). On subsequent trials, subjects attempted to enter the sequence nine more times (trials $2-10)$. An incorrect keystroke caused a temporary black-out of the CRT; an invalid keystroke caused a "beep" to sound. The test was scored for total number of errors made across the ten trials.

\section{Stanford steepiness scale}

Subjects chose a statement which they felt accurately described their current level of alertness by pressing the number on the keypad corresponding to one of seven statements (ranging from $1=$ "Wide awake" to $7=$ "Almost in reverie").

Each of the above tasks was preceded by instructions appearing on the CRT.

\section{Symptom checklist}

Subjects were asked to indicate whether they were currently experiencing any of the following symptoms by responding "yes" or "no": headache, dizziness, nervousness, lightheadedness, incoordination, nausea/vomiting, anxiety, sweating, panic, abnormal vision, agitation, and pain where the catheter was inserted. For each item to which subjects responded "Yes," they were then asked whether the symptom was mild, moderate or severe. The list of symptoms includes those most commonly reported for triazolam, zolpidem, and/or flumazenil (Physician's Desk Reference 1994). The symptom checklist was administered at 0700 hours (pre-drug), 2.5 h postoral drug (near estimated peak effects), and $7.5 \mathrm{~h}$ post-oral drug (after drug effects were expected to have dissipated). Responses were scored as follows: No $=0 ;$ Yes $/$ mild $=1 ;$ Yes $/$ moderate $=2 ;$ Yes $/$ severe $=3$.

\section{Polysomnographic apparatus}

Oxford Medilog 9000-II recording units (Oxford Medical Systems, Oxon, England) were used to record polysomnographic signals that were stored on audio cassettes. Nap sleep data are not presented here.

\section{Sleep chamber}

A continuously ventilated chamber was used for the daytime nap. Ambient noise and lighting were approximately $85 \mathrm{~dB}$ SPL and 340 lux, respectively. Chamber temperature and humidity were $22.0^{\circ} \mathrm{C}$ and $40 \%$, respectively.

A second, identical chamber was used for sleep the night prior to drug administration. Ambient noise, chamber temperature and humidity were $65 \mathrm{~dB}, 24.0^{\circ} \mathrm{C}$ and $40 \%$, respectively.

\section{Procedure}

Subjects participated in groups of two to four. They reported to the laboratory at 1900 hours the evening prior to drug administration. Vital signs (sitting blood pressure and pulse) were measured. Next, Oxford tin-cup electrodes used for recording polysomnograms were attached, and continuous polysomnographic recordings began at 2000 hours. Subjects then received one practice list of Restricted Reminding and three practice sessions of computerized tasks (Repeated Acquisition and Stanford Sleepiness Scale). Decaffeinated food and beverages were allowed ad libitum until 2200 hours, at which time food and beverage intake was prohibited (except ad libitum water) until dinner the following day (approximately $20 \mathrm{~h}$ without food). Lights out was at midnight.

Subjects were awakened the following morning at 0600 hours. Urine for drug screening was collected, then electrodes were checked and repaired. The symptoms checklist was administered and measurement of vital signs was taken at 0700 hours. Next, an indwelling catheter for intravenous drug administration was inserted into the antecubital vein of the left arm.

Cognitive testing began at 0900 hours (pre-drug test) with RRT, $\mathrm{P}-\mathrm{A}$, and PAB tests administered respectively. At 1000 hours, oral drug (20 mg zolpidem, $0.5 \mathrm{mg}$ triazolam, or placebo) was administered in a double-blind manner. Subjects were immediately escorted to the daytime nap chamber and instructed to try to sleep - the chamber was noisy and well lit (as described above), and subjects were required to sit upright in the chairs. The nap served two purposes: (a) it provided a standard environment for occupying the time between drug administration and estimated peak drug effects; (b) it constituted a simulated "worst case" scenario during a military deployment, i.e., the need to perform quickly upon awakening when drug effects were estimated to be maximal, and when sleep inertia effects were expected to negatively affect performance (Balkin et al. 1989). Exactly $1.5 \mathrm{~h}$ post-oral drug, subjects received either flumazenil $(1.0 \mathrm{mg} / 10 \mathrm{ml})$ or placebo $(10 \mathrm{ml}$ normal saline $)$ intravenously over $1.5 \mathrm{~min}$. Three minutes after the injection was completed, subjects were awakened if asleep and tested on the simulated escape test followed by RRT, delayed recall of the first P-A list, immediate recall of a new $\mathrm{P}-\mathrm{A}$ list, and the $\mathrm{PAB}$. Administration of all tests took approximately $45 \mathrm{~min}$. The indwelling catheter was removed approximately $1 \mathrm{~h}$ post-IV dose, followed by vital signs and the symptoms checklist. Restricted Reminding (RRT) and PAB tests were administered at 3 and $4.5 \mathrm{~h}$ post-oral dose $(1.5$ and $3 \mathrm{~h}$ post-IV dose, respectively). Six hours post-triazolam, zolpidem or placebo ( $4.5 \mathrm{~h}$ post-IV dose), subjects were tested on the simulated escape test; however, this time directional arrows were removed. Subjects were unaware that they would be asked to recall the escape route and hence this second test constituted a measure of incidental memory. Next, they were tested on RRT, delayed recall of both P-A lists, and the PAB. Electrodes were then removed. Subjects underwent a brief physical exam, were given a meal, then were administered the symptoms checklist. They were debriefed and released at 1830 hours.

To help maintain motivation and thereby maximize performance throughout the study, subjects were informed that they could earn a $\$ 50.00$ bonus if their performance on the computerized test exceeded a criterion. They were not told the criterion $(60 \%$ accuracy on repeated acquisition during the pre-drug test session) until after the study. As anticipated, all subjects earned the bonus.

\section{Statistical analyses}

Univariate analyses of variance (ANOVA) were conducted on dependent measures using the BMDP statistical package (Dixon 1985), and included one or more of the following factors (as appropriate): drug [six levels = oral placebo + IV placebo (P-P); zolpidem $20 \mathrm{mg}+\mathrm{IV}$ placebo (Z-P); triazolam $0.5 \mathrm{mg}+\mathrm{IV}$ placebo (T-P); oral placebo + IV flumazenil (P-F); zolpidem $20 \mathrm{mg}+\mathrm{IV}$ flumazenil (Z-F); triazolam $0.5 \mathrm{mg}+$ IV flumazenil (T-F)], session (five levels = pre-drug, $1.5,3,4.5$, and $6 \mathrm{~h}$ post-oral drug), and trial (P-A data only; three levels within each immediate recall session $=$ trials 1,2, and 3) with Greenhouse-Geisser adjustments. Significant interactions were followed by simple effects analyses. Post-hoc comparisons among means were conducted using Tukey HSD (equal cell sizes) or Spjotvoll and Stoline's test (unequal cell sizes, sleep data only - see below), where appropriate (Kirk 1982). Symptom checklist and Stanford Sleepiness Scale responses were analyzed using the Kruskal-Wallis test (factor = drug group) for nonparametric data. Unless otherwise noted, statistical significance was $P<0.05$. 


\section{Results}

One subject (P-P group) tested positive for opiates. Exclusion of this subject did not alter statistical outcomes; therefore his data were included in results reported below.

\section{Restricted reminding}

\section{Total misses}

Figure 1 (panel A) illustrates mean total misses across sessions for each drug combination. As shown, all groups performed similarly at the pre-drug session. At $1.5 \mathrm{~h}$ post-oral dose, triazolam and zolpidem increased total misses, an effect which was blocked by flumazenil.

A

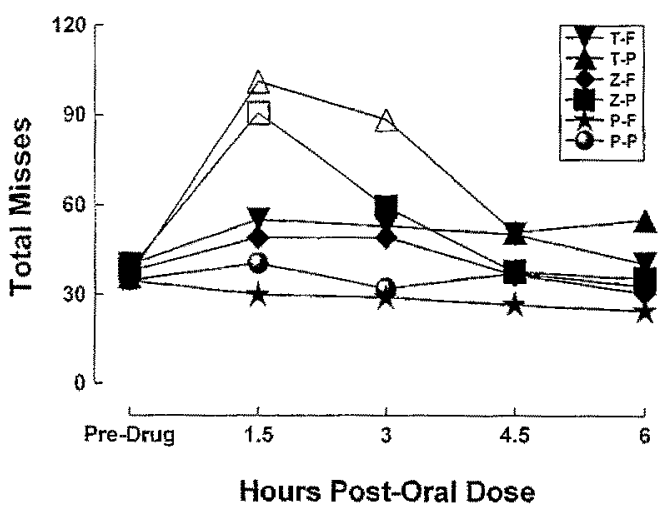

B

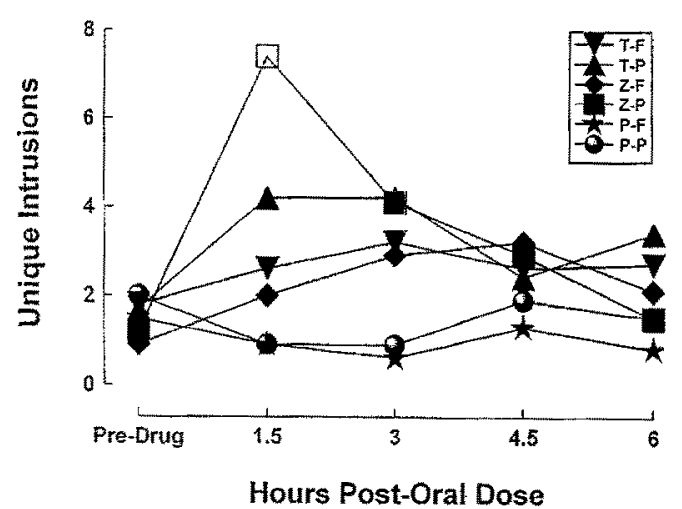

Fig. $1 \mathrm{~A}$ Mean total misses on the Restricted Reminding test for each drug group across sessions. T-P triazolam/placebo, $Z$ - $P$ zolpidem/placebo, $P$ - $P$ placebo/placebo, $T-F$ triazolam/ flumazenil, $Z-F$ zolpidem/flumazenil, $P-F$ placebo/flumazenil. Open symbols indicate groups significantly different from placebo $(P-P)$ at the corresponding session. B Mean unique intrusions on the Restricted Reminding test across sessions. Drug groups and notations are same as panel $\mathbf{A}$
Triazolam's memory-impairing effect at $3 \mathrm{~h}$ post-oral dose also was blocked by flumazenil while zolpidem's memory-impairing effects had dissipated. No drug effects were evident at 4.5 or $6 \mathrm{~h}$ post-oral dose.

\section{Intrusions}

Mean number of intrusions are illustrated in Fig. 1 (panel B). As shown, few intrusions were produced prior to drug administration. At $1.5 \mathrm{~h}$ post-oral dose, zolpidem increased intrusions, an effect which was blocked by flumazenil. At $3 \mathrm{~h}$ post-oral dose, both zolpidem and triazolam increased intrusions compared to P-F but not P-P. This effect also was reversed by flumazenil. Intrusions did not differ among groups at 4.5 or $6 \mathrm{~h}$ post-oral dose.

\section{Paired-associates}

\section{Immediate recall}

Figure 2 (panel A) illustrates mean number of correctly recalled associates (averaged across trials 1-3) prior to drug and at $1.5 \mathrm{~h}$ post-oral dose. As shown, groups did not differ prior to drug. However, at $1.5 \mathrm{~h}$ post-oral dose, immediate recall was impaired by triazolam and zolpidem. This effect was blocked by flumazenil.

Recall for all groups at both sessions improved across trials $1-3$, as indicated by a significant main effect of trials $(P<0.05)$. The Trial $\times$ Drug and Trial $\times$ Session interactions were not significant $\left(P_{\mathrm{S}}>0.05\right)$.

\section{Delayed recall}

Delayed recall for pre-drug items was unaffected by drug group. Delayed recall for pairs originally presented $1.5 \mathrm{~h}$ post-oral dose was impaired by both triazolam $($ mean $=3.8)$ and zolpidem $($ mean $=4.4)$, but only compared to P-F (mean $=9.1$ ) and not P-P (mean $=7.9)$. Flumazenil improved delayed recall in $\mathrm{T}-\mathrm{F}$ and $\mathrm{Z}-\mathrm{F}$ (means $=7.0$ and 6.0 , respectively) compared to P-P, while recall in Z-F was worse than P-F.

Simulated escape

\section{Wrong turns}

Figure 2 (panel B) illustrates mean number of wrong turns at 1.5 and $6 \mathrm{~h}$ post-oral dose for each group. Few wrong turns were made by any group at $1.5 \mathrm{~h}$ post-oral dose, although the Z-P group differed from groups making no wrong turns. However, at $6 \mathrm{~h}$ post-oral dose, both triazolam and zolpidem increased wrong turns, an effect which was blocked by flumazenil. 


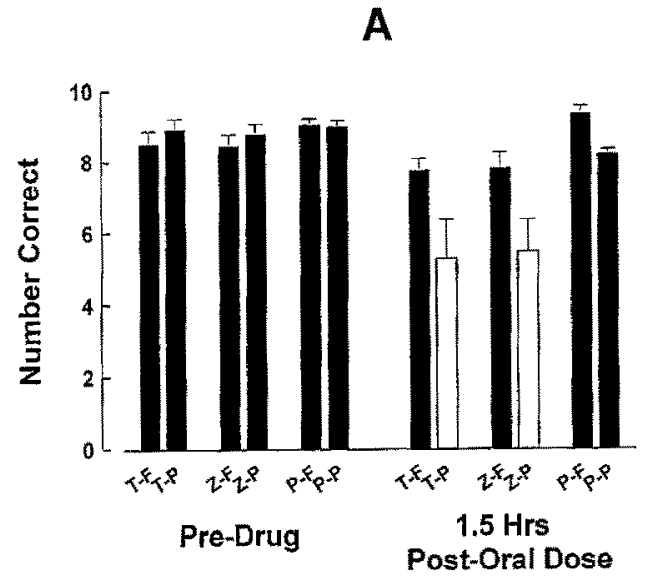

B

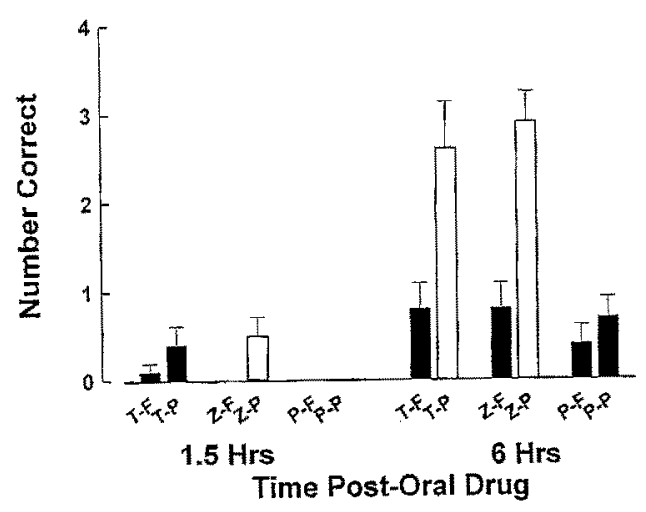

Fig. 2 A Mean number of correctly recalled associates ( \pm SEM; collapsed across immediate recall trials 1-3) on the PairedAssociates test pre-drug and at $1.5 \mathrm{~h}$ post-oral dose. Drug groups are same as Fig. 1 A. Open bars indicate groups significantly different from placebo $(P-P)$ at the corresponding session. B Mean number of wrong turns ( \pm SEM) on the Simulated Escape test at 1.5 (with arrows) and $6 \mathrm{~h}$ (without arrows) post-oral dose. Drug groups are same as Fig. 1 A; other notations are same as Fig. 2 Panel A

\section{Repeated acquisition (PAB)}

\section{Number of errors}

All groups performed similarly at the pre-drug session, although Z-P and P-P made more errors than P-F (mean $=75.6$ and 78.7 versus 42.7 errors, respectively). At $1.5 \mathrm{~h}$ post-oral dose, triazolam and zolpidem increased errors (mean $=124.9$ and 119.8 , respectively) compared to P-P and P-F (mean $=73.4$ and 47.2). This effect was blocked by flumazenil (means $=100.3$ and 79.3 for T-F and Z-F, respectively). Errors did not differ among groups at $3,4.5$, or $6 \mathrm{~h}$ post-oral dose.

Results of the ANOVAs for the above learning/memory tests (Restricted Reminding, Paired-Associates, Simulated Escape, and Repeated Acquisition) are summarized in Table 1.
Subjective ratings

Ratings for side effects (dizziness, lightheadedness, and incoordination) and sleepiness scores from the Stanford Sleepiness Scale are listed in Table 2.

\section{Side effects}

Ratings of dizziness, lightheadedness, and incoordination were increased at $2.5 \mathrm{~h}$ post-oral dose by triazolam and zolpidem. These effects were blocked by flumazenil. Ratings did not differ among other groups at any time.

\section{Stanford sleepiness scale}

Prior to drug administration, mean sleepiness scores were low and did not differ among groups. At 1.5 and $3 \mathrm{~h}$ post-oral dose, triazolam and zolpidem increased sleepiness scores. These effects were blocked by flumazenil. Sleepiness ratings did not differ among groups at 4.5 or $6 \mathrm{~h}$ post-oral dose.

\section{Discussion}

Triazolam $0.5 \mathrm{mg}$ and zolpidem $20 \mathrm{mg}$ impaired memory at estimated peak plasma concentrations, consistent with previous findings (O'Donnell et al. 1988; Balkin et al. 1992). Triazolam continued to impair memory up to 6 hours after administration, while the effect of zolpidem on memory dissipated by $3 \mathrm{~h}$ postadministration. Memory at $1.5 \mathrm{~h}$ post-oral dose (time of estimated peak triazolam and zolpidem concentrations) for pre-drug items was unaffected by triazolam or zolpidem. These results corroborate previous reports (e.g., O'Donnell et al. 1988) indicating that acquisition and/or consolidation processes (rather than recall processes) are impaired by benzodiazepine receptor agonists. In addition, the results indicate a longer duration of amnestic effects for triazolam $0.5 \mathrm{mg}$ than for zolpidem $20 \mathrm{mg}$, a finding reported previously for triazolam $0.25 \mathrm{mg}$ versus zolpidem $10 \mathrm{mg}$ (Berlin et al. 1993). A previous study demonstrated that triazolam $0.5 \mathrm{mg}$ and zolpidem $20 \mathrm{mg}$ are hypnotically equivalent in healthy young males during a daytime nap occurring from 2.5 to $6 \mathrm{~h}$ post-dosage (Balkin et al. 1992).

The benzodiazepine antagonist flumazenil blocked the memory-impairing effects of both the $\mathrm{BZ}$ receptor subtype-nonspecific agonist triazolam and the BZ-1 receptor subtype-specific agonist zolpidem, at estimated peak plasma concentrations $(1.5 \mathrm{~h}$ post-triazolam or zolpidem). Flumazenil blocked the effects of triazolam and zolpidem on explicit memory (i.e., Paired-Associates and Restricted Reminding) as well 
Table 1 Results of ANOVA for memory tasks

\begin{tabular}{|c|c|c|c|c|c|c|c|}
\hline \multirow[t]{2}{*}{ Task/Variable } & \multirow{2}{*}{$\begin{array}{l}\text { Drug effect } \\
F(d f)\end{array}$} & \multirow[b]{2}{*}{$P$} & \multirow{2}{*}{$\begin{array}{l}\text { Session effect } \\
F(d f)\end{array}$} & \multirow[b]{2}{*}{$P$} & \multicolumn{2}{|c|}{ Drug $\times$ session effect } & \multirow{2}{*}{$\begin{array}{l}\text { Post-hoc test } \\
\text { (Critical diff.) }\end{array}$} \\
\hline & & & & & $F(d f)$ & $P$ & \\
\hline RRT/Total misses & $8.99(5,54)$ & 0.000 & $34.94(4,216)$ & 0.000 & $7.62(20,216)$ & 0.000 & \\
\hline Simple effect of drug at $1.5 \mathrm{~h}$ post* & $4.31(5,54)$ & 0.000 & & & & & 32.67 \\
\hline Simple effect of drug at $3 \mathrm{~h}$ post & $10.09(5,54)$ & 0.000 & & & & & 29.13 \\
\hline Simple effect of drug at $4.5 \mathrm{~h}$ post & $2.97(5,54)$ & 0.019 & & & & & 23.08 \\
\hline Simple effect of drug at $6 \mathrm{~h}$ post & $4.27(5.54)$ & 0.002 & & & & & 22.67 \\
\hline RRT/Unique intrusions & $2.92(5,54)$ & 0.021 & $4.61(4,216)$ & 0.006 & $3.26(20,216)$ & 0.000 & \\
\hline Simple effect of drug at $1.5 \mathrm{~h}$ post & $4.07(5,54)$ & 0.003 & & & & & 5.30 \\
\hline Simple effect of drug at $3 \mathrm{~h}$ post & $3.94(5,54)$ & 0.004 & & & & & 3.38 \\
\hline Simple effect of drug at $4.5 \hat{\mathrm{h}}$ post & $0.93(5,54)$ & NS & & & & & - \\
\hline Simple effect of drug at $6 \mathrm{~h}$ post & $2.64(5,54)$ & 0.033 & & & & & 2.49 \\
\hline P-A/Immediate recall & $4.54(5,54)$ & 0.002 & $36.51(1,54)$ & 0.000 & $7.34(5,54)$ & 0.000 & \\
\hline Simple effect of drug at $1.5 \mathrm{~h}$ post & $6.44(5,54)$ & 0.000 & & & & & 2.75 \\
\hline P-A/Delayed recall of pre-drug items & $1.81(5,54)$ & NS & $0.03(1,54)$ & NS & $0.96(5,54)$ & NS & \\
\hline P-A/Delayed recall of post-drug items & $10.13(5,54)$ & 0.000 & & & & & \\
\hline Repeated Acquisition/Errors & $2.95(5,54)$ & 0.020 & $22.13(4,216)$ & 0.000 & $3.34(20,216)$ & 0.000 & \\
\hline Simple effect of drug at $1.5 \mathrm{~h}$ post & $7.93(5,54)$ & 0.000 & & & & & 45.55 \\
\hline Simple effect of drug at $3 \mathrm{~h}$ post & $2.21(5,54)$ & NS & & & & & - \\
\hline Simple effect of drug at $4.5 \mathrm{~h}$ post & $1.44(5,54)$ & NS & & & & & - \\
\hline Simple effect of drug at $6 \mathrm{~h}$ post & $1.51(5,54)$ & NS & & & & & - \\
\hline Simulated Escape/Wrong turns at $1.5 \mathrm{~h}^{\mathrm{b}}$ post & $2.79(5,54)$ & 0.026 & & & & & 0.58 \\
\hline Simulated Escape/Wrong turns at $6 \mathrm{~h}^{\mathrm{c}}$ post & $10.43(5,54)$ & 0.000 & & & & & 1.45 \\
\hline
\end{tabular}

${ }^{a}$ Post-oral dose ${ }^{b}$ With arrows ${ }^{c}$ Without arrows

Table 2 Side Effects and Sleepiness Scores

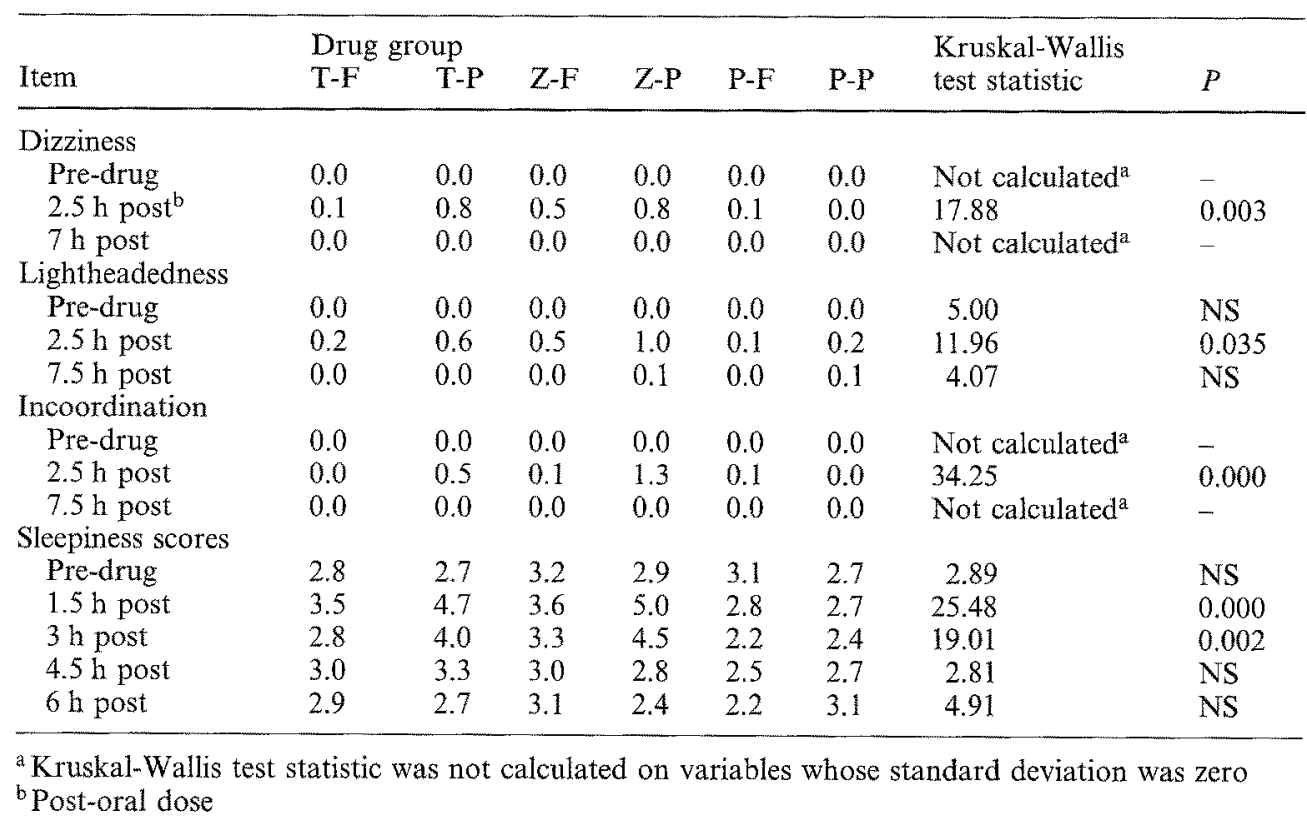

as incidental memory (as measured by recall of the Escape Task route). These results confirm previous findings which indicate flumazenil's antagonism of the effects of benzodiazepines on explicit memory (Dorow et al. 1987; Dunton et al. 1988; Gentil et al. 1989; Short and Galletly 1989; Preston et al. 1989; McKay et al. 1990). In addition, flumazenil blocked the zolpideminduced intrusions (errors of commission) on the Restricted Reminding task. Preston et al. (1989) also found that flumazenil blocked lorazepam-induced errors of commission on a similar task. Taken together, these findings extend flumazenil's action to include antagonism of (1) non-benzodiazepine agonists; (2) BZ receptor subtype-specific drugs, (3) BZ agonist effects on incidental memory; and (4) BZ agonist-induced disinhibition of responding (as has been found previously in animals - e.g. Bonetti et al. 1982).

Flumazenil blocked triazolam's effects on memory at $3,4.5$, and $6 \mathrm{~h}$ post-triazolam administration (corresponding to $1.5,3$, and $4.5 \mathrm{~h}$ post-flumazenil). This was unexpected, given flumazenil's short half-life (approximately $1 \mathrm{~h}$ - Klotz et al. 1984), but may be due 
to the relatively high dose of flumazenil used in conjunction with dissipation of triazolam's memoryimpairing effects across time. Although not evaluated in the present study, other studies have shown that flumazenil does not interact pharmacokinetically with diazepam (O'Boyle et al. 1983), midazolam (Lauven et al. 1985), or zolpidem (Patat et al. 1994). Thus, flumazenil's reversal of memory-impairing effects caused by triazolam and zolpidem is assumed to occur via pharmacodynamic antagonism at the benzodiazepine receptor (Patat et al. 1994).

Nonsignificant trends for best post-sleep memory and lowest sleepiness scores were evident in the group receiving oral placebo followed by flumazenil (see Figs. 1 and 2 and Table 2). In fact, differences may have been obscured by the apparent insensitivity of the PA test (in which ceiling effects were evident for the P$\mathrm{F}$ group at $1.5 \mathrm{~h}$ post-dose - Fig. 2 panel A. These trends suggest either (1) that flumazenil in fact possesses intrinsic inverse agonist properties, or (2) that an endogenous benzodiazepine agonist (Unseld et al. 1990) mediates some sleep-related phenomena including "sleep inertia" (post-sleep performance decrements), and that flumazenil reversed these effects after the daytime nap by blocking the endogenous ligand. Although highly speculative, the latter hypothesis is indirectly supported by a study which showed that distribution of benzodiazepine receptors in anterior cortical regions (Young et al. 1981) corresponds to those areas which remain metabolically suppressed for some time after awakening from sleep. The latter suggests that these areas may be involved in the "sleep inertia" effect (Balkin, manuscript in preparation).

The present study demonstrates the utility of flumazenil for rapidly reversing $\mathrm{BZ}$ agonist-induced memory impairment in situations which might be encountered by individuals taking benzodiazepines to aid sleep (e.g., during transoceanic flights). However, an intravenous preparation (as was used in the present study) would not be practical for most applications. Although not commercially available at this time, flumazenil can be administered orally. An oral dose of flumazenil should be as effective as the intravenous preparation, given adequate plasma concentrations. However, antagonism of benzodiazepine receptor agonists would be relatively delayed, since the time to peak plasma concentrations following an oral dose is $20-90$ min (Roncari et al. 1986). Flumazenil has been investigated for use as a treatment for benzodiazepine withdrawal (Gallager et al. 1986; File and Baldwin, 1987), as a reversal agent for coma due to hepatic encephalopathy (Grimm et al. 1988; Meier and Gyr, 1988) and idiopathic recurring stupor (Rothstein et al. 1992); and as an alternative to benzodiazepine treatment for epilepsy (Sharief et al. 1993). Other uses of flumazenil which merit investigation include prevention of tolerance to the hypnotic and anticonvulsant properties of benzodiazepines, and as an antidote to next-day impairment caused by longer-acting benzodiazepine hypnotics.

Thus, memory impairment caused by the potent short-acting hypnotics triazolam and zolpidem are rapidly reversed by flumazenil, presumably via antagonism at the benzodiazepine receptor. Dose-response information was not generated in the present study. Curran and Birch (1991), however, failed to find reversal effects using $0.5 \mathrm{mg}$ flumazenil. Their negative findings, considered with the present results, suggest that $1 \mathrm{mg}$ intravenous flumazenil is the minimally effective dose for reversing $\mathrm{BZ}$ receptor agonist-induced memory impairment. Blockade at the benzodiazepine receptor (of an endogenous ligand) may account for the nonsignificant improvement in post-sleep performance for subjects receiving flumazenil alone.

Acknowledgements This material has been reviewed by the Walter Reed Army Institute of Research, and there is no objection to its presentation and/or publication. The opinions or assertions contained herein are the private views of the authors and are not to be construed as official or as reflecting the position of the Department of the Army or the Department of Defense. The study was approved by the Office of the Surgeon General Human Use and Review Board, United States Army Research and Development Command.

\section{References}

Balkin TJ, O'Donnell VM, Kamimori GH, Redmond DP, Belenky $G$ (1989) Sleep inertia following triazolam-induced recovery sleep. Hum Psychopharmacol 4:291-296

Baikin TI, O'Donnell VM, Wesensten N, McCann U, Belenky G (1992) Comparison of the daytime sleep and performance effects of zolpidem versus triazolam. Psychopharmacology 107: $83-88$

Berlin I, Warot D, Hergueta T, Molinier P, Bagot C, Puech AJ (1993) Comparison of the effects of zolpidem and triazolam on memory functions, psychomotor performances, and postural sway in healthy subjects. J Clin Psychopharmacol 13: 100-106

Bonetti EP, Pieri L, Cumin R, Schaffner R, Pieri M, Gamzu ER, Muller RKM, Haefely W (1982) Benzodiazepine antagonist Ro 15-1788: neurological and behavioral effects. Psychopharmacology $78: 8-18$

Brogden RN, Goa KL (1991) Flumazenil. A reappraisal of its pharmacological properties and therapeutic efficacy as a benzodiazepine antagonist. Drugs 42:1061-1089

Burkhart KK, Kulig KW (1990) The diagnostic utility of flumazenil (a benzodiazepine antagonist) in coma of unknown etiology. Ann Emerg Med 19:319-321

Buschke H, Fuld PA (1974) Evaluating storage, retention, and retrieval in disordered memory and learning. Neurology $24: 1019-1025$

Curran HV, Birch B (1991) Differentiating the sedative, psychomotor and amnestic effects of benzodiazepines: a study with midazolam and the benzodiazepine antagonist, flumazenil. Psychopharmacology 103:519-523

Darragh A, Lambe R, Kenny M, Brick I (1983) Tolerance of healthy volunteers to intravenous administration of the benzodiazepine antagonist Ro 15-1788. Eur J Clin Pharmacol 24:569-570

Dixon WJ (1985) BMDP statistical software manual. University of California Press, Berkeley, Los Angeles, London.

Dorow R, Berenberg D, Duka T, Sauerbrey N (1987) Amnestic effects of lormetazepam and their reversal by the benzodiazepine antagonist Ro 15-1788. Psychopharmacology 93:507-514 
Dunton AW, Schwam E, Pitman V, McGrath J, Hendler J, Siegel J (1988) Flumazenil: U.S. clinical pharmacology studies. Eur J Anaesthesiol S2:81-95

Farb DH, Borden LA, Chan CY, Czajkowski CM, Gibbs TT, Schiller GD (1984) Modulation of neuronal function through benzodiazepine receptors: biochemical and electrophysiological studies of neurons in primary monolayer cell culture. Ann NY Acad Sci 435:1-31

File SE, Baldwin HA (1987) Flumazenil: a possible treatment for benzodiazepine withdrawal anxiety. Lancet $2: 106-107$

File SE, Pellow S (1986) Intrinsic actions of the benzodiazepine receptor antagonist Ro 15-1788. Psychopharmacology 88:1-11

Friedman H, Greenblatt DJ, Burstein ES, Harmatz JS, Shader RI (1986) Population study of triazolam pharmacokinetics. Br J Clin Pharmacol 22:639-642

Gallager DW, Heninger K, Heninger G (1986) Periodic benzodiazepine antagonist administration prevents benzodiazepine withdrawal symptoms in primates. Eur J Pharmacol 132:31-38

Gentil V, Gorenstein C, Camargo CHP, Singer JM (1989) Effects of flunitrazepam on memory and their reversal by two antagonists. J Clin Psychopharmacol 9:191-197

Ghoneim MM (1992) The reversal of benzodiazepine-induced amnesia by flumazenil: a review. Curr Ther Res 52:757-767

Grimm G, Katzenschlager R, Holzner F, Ferenci P, Schneeweiss B, Laggner A, Lenz K, Druml W, Madl C (1988) Effect of flumazenil in hepatic encephalopathy. Eur $\mathbf{J}$ Anaesthesiol S2:147-149

Kelly C, Egner J, Rubin J (1988) Successful treatment of triazolam overdose with Ro 15-1788. S Afr Med J 73:442

Kirk RE (1982) Experimental design: procedures for the behavioral sciences, 2nd edn. Brooks/Cole, Belmont, Calif.

Klotz U, Ziegler G, Reimann IW (1984) Pharmacokinetics of the selective benzodiazepine antagonist Ro $15-1788$ in man. Eur J Clin Pharmacol 27:115-117

Langer SZ, Arbilla S, Scatton B, Niddam R, Dubois A (1988) Receptors involved in the mechanism of action of zolpidem. In: Sauvanet JP, Langer SZ, Morselli PL (eds) Imidazopyridines in sleep disorders: a novel experimental and therapeutic approach (L.E.R.S. Monograph Series Volume 6). Raven Press, New York, pp 55-70

Lauven PM, Schwilden H, Stoeckel H, Greenblatt, DJ (1985) The effects of a benzodiazepine antagonist Ro 15-1788 in the presence of stable concentrations of midazolam. Anesthesiology $63: 61-64$

Lheureux P, Debailleul G, De Witte O, Askenasi R (1990) Zolpidem intoxication mimicking narcotic overdose: response to flumazeni1. Hum Exp Toxicol 9:105-107

McKay AC, McKinney MS, Clarke RSJ (1990) Effect of flumazenil on midazolam-induced amnesia. Br J Anaesth 65:190-196

Meier R, Gyr K (1988) Treatment of hepatic encephalopathy (HE) with the benzodiazepine antagonist flumazenil: a pilot study. Eur J Anaesthesiol S2:139-146

O'Boyle C, Lambe R, Darragh A, Taffe W, Brick I, Kenny M (1983) Ro 15-1788 antagonizes the effects of diazepam in man without affecting its bioavailability. Br J Anaesth 55:349-355

O'Donnell VM (1981) Neurochemical correlates of memory function in Korsakof's syndrome and Alzheimer's disease. PhD the- sis, Department of Psychology, University of Houston, Houston, Texas

O'Donnell VM, Balkin TJ, Andrade JR, Simon LM, Kamimori GH, Redmond DP, Belenky G (1988) Effects of triazolam on performance and sleep in a model of transient insomnia. Hum Perform 1:146-160

Patat A, Naef MM, Van Gessel E, Forster A, Dubruc C, Rosenzweig P (1994) Flumazenil antagonizes the central effects of zolpidem, an imidazopyridine hypnotic. Clin Pharmacol Ther $6: 430-436$

Penetar D, Belenky G, Garigan JJ, Redmond DP (1989) Triazolam impairs learning and fails to improve sleep in a long-range aerial deployment. Aviat Space Env Med 60:594-598

Physician's Desk Reference (1994) PDR(R) Library on CDROM(TM). Medical Economics Company, Montvale, N.J.

Polc P, Laurent JP, Scherschlicht R, Haefeley W (1981) Electrophysiological studies on the specific benzodiazepine antagonist Ro 15-1788. Arch Pharmacol 316:317-325

Preston GC, Ward CE, Broks P, Traub M, Stahl SM (1989) Effects of lorazepam on memory, attention and sedation in man: antagonism by Ro 15-1788. Psychopharmacology 97:222-227

Roehrs T, Merlotti L, Zorick F, Roth T (1994) Sedative, memory, and performance effects of hypnotics. Psychopharmacology $116: 130-134$

Roncari G, Ziegler WH, Guentert TW (1986) Pharmacokinetics of the new benzodiazepine antagonist Ro 15-1788 in man following intravenous and oral administration. $\mathrm{Br} \mathrm{J}$ Clin Pharmacol $22: 421-428$

Rothstein JD, Guidotti A, Tinuper P, Cortelli P, Avoni P, Plazzi G, Lugaresi E, Schoch P, Montagna P (1992) Endogenous benzodiazepine receptor ligands in idiopathic recurring stupor. Lancet 340:1002-1004

Sharief MK, Sander JWAS, Shorvon SD (1993) The effect of oral fumazenil on interictal epileptic activity: results of a doubleblind, placebo-controlled study. Epilepsy Res 15:53-60

Short TG, Galletly DC (1989) Residual psychomotor effects following reversal of midazolam sedation with fumazenil. Anaesth Intensive Care 17:290-297

Siegart W, Schuster A (1984) Affinity of various ligands for benzodiazepine receptors in rat cerebellum and hippocampus. Biochem Pharmacol 33:4033-4038

Thenot JP, Hermann P, Durand A, Burke JT, Allen J, Garrigou D, Vajta S, Albin H, Thebault JJ, Olive G, Warrington SJ (1988) Pharmacokinetics and metabolism of zolpidem in various animal species and in humans. In: Sauvanet JP, Langer SZ, Morselli PL (eds) Imidazopyridines in sleep disorders: A novel experimental and therapeutic approach (L.E.R.S. Monograph Series Volume 6). Raven Press, New York, pp 139-153

Thorne DR, Genser SG, Sing HC, Hegge FW (1985) The Walter Reed performance assessment battery. Neurobehav Toxicol Teratol $7: 415-418$

Unseld E, Fischer C, Rothemund E, Klotz U (1990) Occurrence of "natural" diazepam in human brain. Biochem Pharmacol 39: $210-212$

Young WS, Niehoff D, Kuhar MJ, Beer B, Lippa AS (1981) Multiple benzodiazepine receptor localization by light microscopic radiohistochemistry. J Pharmacol Exp Ther 216:425-430 